\section{Epidemiology and regional differences of acute poisonings of eight cities in Gyeonggi-do province in Korea using data from the National Emergency Department Information System of Korea}

\author{
Seungho Ham, Young Gi Min, Minjung Kathy Chae, Hyuk-Hoon Kim \\ Department of Emergency Medicine, Ajou University School of Medicine, Suwon, Korea
}

Objective We aimed to analyze the differences in epidemiological aspects and clinical courses of acute poisonings in each region of the Gyeonggi-do province in Korea.

Methods This retrospective study analyzed data from the National Emergency Department Information System of Korea. We retrospectively reviewed cases of acute poisonings between April 2006 and March 2015 recorded at 13 emergency departments in eight different cities of Gyeonggi-do province in Korea. The differences in the incidence, age distribution, causative agent, and clinical course of poisonings among regions were the main outcomes measured.

Results The proportion of poisonings in the $\leq 9$ age group was high in Yongin (17.44\%) and that in $\geq 65$ age group was high in Gwangmyeong (21.76\%). The proportion of cases involving carbon monoxide was high in Ansan (8.82\%) in patients hospitalized and the proportion of cases involving pesticides was high in Pyeongtaek (52.78\%) in patients admitted to the intensive care unit. The admission rate of poisoned patients was high in Osan (36.02\%).

Conclusion In this study, differences in the characteristics of poisoned patients between 8 cities were noted. Therefore, hospitals need to arrange treatment resources for poisoned patients according to the characteristics of the specific region. The results of this study may serve as evidence for new strategies to prepare for the acute poisonings in hospitals.

Keywords Acute disease; Poisoning; Epidemiologic studies; Republic of Korea
elSSN: 2383-4625

Received: 18 February 2019

Revised: 8 April 2019

Accepted: 17 April 2019

Correspondence to: Hyuk-Hoon Kim Department of Emergency Medicine, Ajou University School of Medicine, 164 Worldcup-ro, Suwon 16499, Korea E-mail: lieben82@ajou.ac.kr ORCID

http://orcid.org/0000-0003-1957-3020



How to cite this article:

Ham S, Min YG, Chae MK, Kim HH. Epidemiology and regional differences of acute poisonings of eight cities in Gyeonggido province in Korea using data from the National Emergency Department Information System of Korea. Clin Exp Emerg Med 2020;7(1):43-51.
This is an Open Access article distributed under the terms of the Creative Commons Attribution Non-Commercial License (http:// creativecommons.org/licenses/by-nc/4.0/). 


Capsule
Wummat is already known
Acute poisoning is a common cause of morbidity and mortality. A treatment given at the appropriate time for poisoned
patients is essential for a favorable prognosis and a clinical course of recovery. To provide timely and proper treatment
in poisoned patients, regional hospitals should have treatment resources tailored to the characteristics of poisonings in
their specific areas. However, there have been few epidemiological studies of poisoned patients by region in Korea.
What is new in the current study
This study analyzed acute poisoning incidents of 8 regions of Gyeonggi-do province in Korea and found differences in
the incidence, age distribution, causative agent, and clinical course of poisonings among regions. The results of this
study may help guide new strategies to prepare for acute poisonings in hospitals.

\section{INTRODUCTION}

Acute poisoning is a common cause of morbidity and mortality. The incidence of accidental and intentional poisonings has been shown to be increasing annually. ${ }^{1}$ It is also considered a major global health problem and a frequent reason for admission to the hospital. ${ }^{2}$ In Korea, poisonings and mortality were most commonly caused by pesticides, and the hospitalization rate for poisoning per 100,000 was the highest in those aged $\geq 65$ years (1.87), especially in men (2.35). ${ }^{1}$

As with other diseases, treatment given at the appropriate time is essential for a favorable prognosis and a clinical course of recovery of a poisoned patient. In some cases of acute poisoning such as poisoning by acetaminophen, opioids, cardiac glycosides, organophosphates and snake bites, an antidote given at the right time may be life-saving and is emphasized. ${ }^{3}$ The characteristics of poisoned patients in each region may be different as the characteristics and distribution of the population, the composition of families, income level, education status, proportions of immigrants, occupation distribution and industrial activities, transportation, religion, geographical location, and climates vary between the regions. ${ }^{4}$ To provide timely and appropriate treatment for poisoned patients, regional hospitals should have treatment resources tailored to the characteristics of poisonings in their specific areas.

The objective of this study was to describe the differences in the epidemiological aspects and clinical courses of acute poisonings in 8 regions of Gyeonggi-do province in Korea. To help to show differences, we performed a comprehensive mapping of the distribution of poisonings using a geographic information system $(\mathrm{GIS})^{5}$

\section{METHODS}

\section{Study design}

This retrospective study analyzed data obtained from the database of the National Emergency Department Information System (NEDIS), Korea.

\section{Study setting and population}

We reviewed cases of acute poisonings between April 2006 and March 2015 recorded at 13 emergency departments of second level or university affiliated hospitals in 8 different cities of Gyeonggi-do province, Korea. We included cases with a clinical history of acute poisonings. The following cases were excluded: those with incomplete data including any missing values, and those of unclear location, in which the correct region could not be identified (Fig. 1).

\section{Database and variables}

NEDIS is an emergency information network operated by the Ministry of Health and Welfare, which includes clinical and administrative data of all patients who have visited the emergency department. In 2013, Korea had a total of 434 emergency institutes which included 20 regional emergency centers (one to two centers in every large city or province), 119 local emergency centers including two special emergency centers (one center per million inhabitants in cities and one per 500,000 people in rural areas), and 293 local emergency institutes. ${ }^{6}$ NEDIS data include information on patient age and sex, marital status, suicidal attempts, time and place of incident, type of toxic agent, types of admission wards (general ward or intensive care unit), clinical course, and the rate of mortality for each region. We defined the children and adolescents as anyone younger than 20 years; they were divided into 


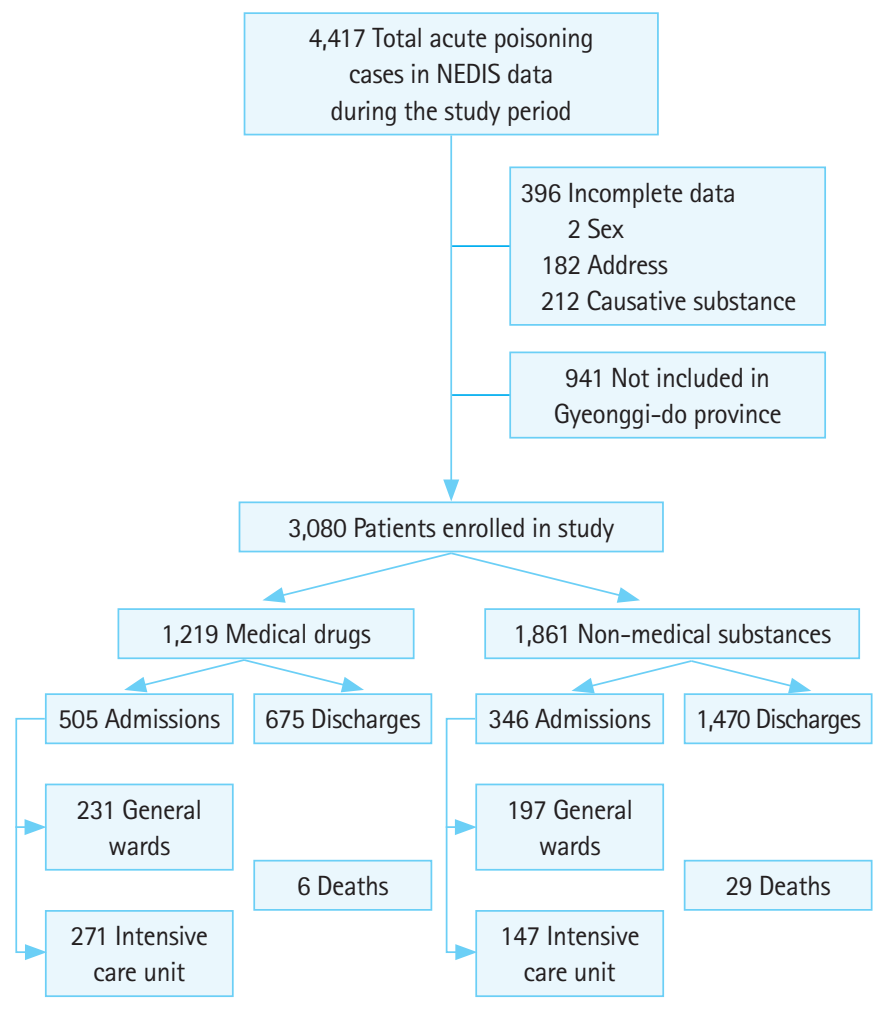

Fig. 1. Flow chart reveals the reason for, and number of, patient inclusions, exclusions, and outcomes. NEDIS, National Emergency Department Information System.

the following age groups: $\leq 9$ years and $10-19$ years. The other adults were divided into the following age groups: $20-64$ years and $\geq 65$ years. Regions of the incident were divided into eight cities based on the administrative address as of 2010 as Ansan, Anyang, Hwasung, Gwangmyeong, Osan, Pyeongtaek, Suwon, and Yongin. Based on the opinions of emergency physicians, causative substances of patients were classified using codes T36-T65 of the International Classification of Diseases, 10th revision.?

\section{Causative substances in cases of acute poisonings}

We classified causative substances as follows: systemic anti-infectives (T36-T37); hormones and their synthetic substitutes (T38); non-opioid analgesics (T39); hallucinogens (T40); antiepileptics, sedative-hypnotic and anti-parkinsonism drugs, and psychotropic drugs, not elsewhere classified (T42, T43); cardiovascular drugs (T46); gastrointestinal drugs (T47); diuretics and other unspecified drugs, medicaments and biological substances (T50); alcohol (T51); organic solvents (T52); corrosive substances (T54); soaps and detergents (T55); metal and inorganic substances (T56-T57); carbon monoxide (T58); gases (T59); pesticides (T60); seafood and food (T61-T62, T64); contact with venomous animals (T63); and unspecified substances (T65).
Table 1. General characteristics of poisoning patients $(n=3,080)$

\begin{tabular}{lrr}
\hline Characteristics & Number & $\%$ \\
\hline Sex & & \\
Male & 1,357 & 44.06 \\
Female & 1,723 & 55.94 \\
Age (yr) & & \\
$\leq 9$ & 401 & 13.02 \\
10-19 & 205 & 6.66 \\
20-64 & 2,033 & 66.00 \\
$\geq 65$ & 441 & 14.32 \\
Marital status & & \\
Married & 1,228 & 39.87 \\
Unmarried & 851 & 27.63 \\
Divorced & 56 & 1.82 \\
Unknown & 945 & 30.68 \\
Intent & & \\
Unintentional & 1,654 & 53.70 \\
Intentional & 1,423 & 46.20 \\
Unknown & 3 & 0.10 \\
Outcome & & \\
Home care & & \\
Admission & 2,145 & 69.64 \\
$\quad$ General ward & & \\
Intensive care unit & 434 & 14.09 \\
Transferred to other hospital & 417 & 13.54 \\
\hline
\end{tabular}

\section{Statistical analysis and data mapping}

All data were analyzed using IBM SPSS Statistics ver. 20 (IBM Corp., Armonk, NY, USA). Incidence location of poisonings in Gyeonggi-do province was mapped using X-Ray Map (BIZGIS Corp., Seoul, Korea). Address data of cases for each location of acute poisoning incident were mapped according to the latitude and longitude coordinates. The frequency of non-mappable records was negligible. All data were assumed to be accurate and complete. A kernel density map was created to allow for a simple visual examination of incident locations and precise identification of hotspots of poisoning. Natural breaks (Jenks' algorithm) were selected to identify areas of high concentration, and the cut-off was automatically adjusted.

\section{Ethics statement}

This study was approved by the institutional review board of Ajou Institutional Review Board (AJIRB-MED-MDB-16-455). The requirement of informed consent from patients was waived due to the retrospective nature of the study.

\section{RESULTS}

\section{General characteristics of acute poisonings}

Overall, 3,080 patients with acute poisoning from 2006 to 2015 
were included. There were more cases of poisoning by non-medical substances $(1,861,60.42 \%)$ than those by medical substances $(1,219,39.58 \%)$. The proportion of patients who were admitted due to poisoning by medical drugs $(505,41.43 \%)$ was higher than due to poisoning by non-medical substances (346, 48.59\%) (Fig. 1). Overall, there were more women $(1,723,55.94 \%)$ than men $(1,357,44.06 \%)$. Of the enrolled patients, 2,033 were $20-64$ years old, comprising $66.00 \%$ of all patients; 1,228 patients (39.87\%) were married. More patients $(1,657,53.80 \%)$ visited the emergency room for unintentional poisoning than for intentional poisoning. A total of 851 (27.63\%) poisoned patients who visited the emergency room were admitted and treated. Of these 851 patients, 434 were cared for in a general ward, while 417 patients were treated in an intensive care unit (Table 1).

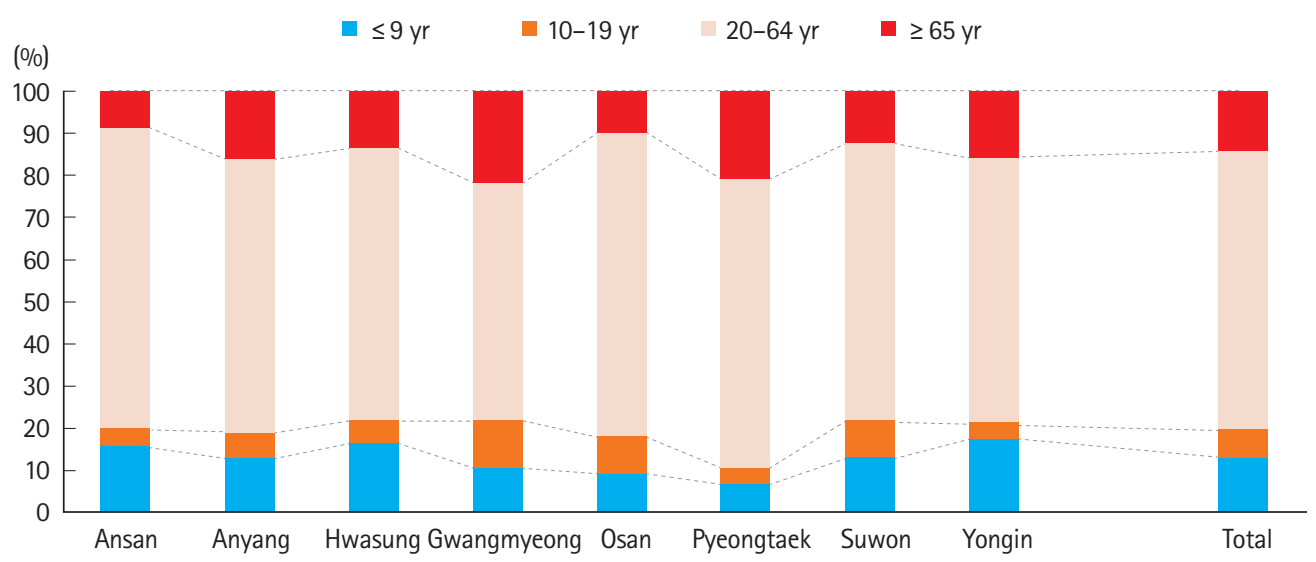

A
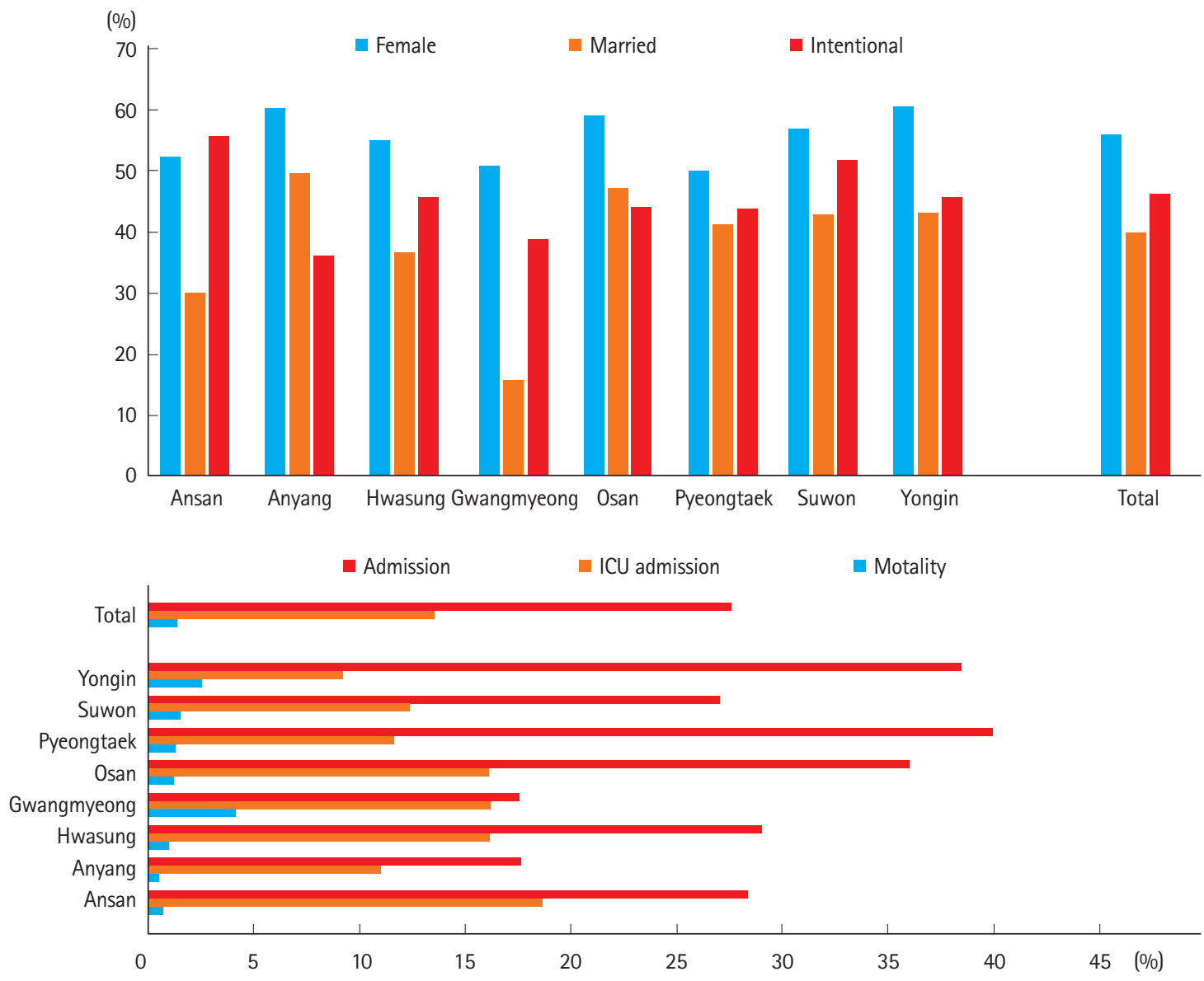

B

\section{C}

Fig. 2. Characteristics of patients with acute poisoning for each region. (A) Regional differences in distributions for each age group. (B) Regional differences in characteristics of poisoned patients. (C) Regional differences in clinical courses. ICU, intensive care unit. 
Regional differences in characteristics of acute poisonings Age distributions of poisonings were different among different regions. Though the overall proportion of $\leq 9$-year age group in patients with poisoning was $13.02 \%(401 / 3,080)$, the proportions in Yongin $(17.44 \%, 34 / 195)$ and Hwasung $(16.41 \%, 65 / 396)$ were higher than the overall proportion. For the 10-19-year age group, proportions of patients in Gwangmyeong (11.11\%, 24/216) were higher than the overall proportion $(6.66 \%, 205 / 3,080)$. Compared to the overall proportion of patients in the $\geq 65$-year age group $(14.32 \%, 441 / 3,080)$, the proportion of older patients with poisoning was higher in Gwangmyeong $(21.76 \%, 47 / 216)$ and Pyeongtaek (20.78\%, 64/308) (Fig. 2A).

Proportions of female poisoned patients were generally higher than those of males in all cities. In Gwangmyeong, the proportion of married patients was $15.74 \%$, which was less than half of the overall proportion $(39.87 \%, 1,228 / 3,080)$. The proportion of intentional poisonings was higher in Ansan $(55.71 \%, 200 / 359)$ than the overall proportion $(46.20 \%, 1,423 / 3,080)$ (Fig. 2B).

\section{Regional differences in the clinical course of acute poisonings}

The proportion of patients who were admitted to the hospital in an emergency room was higher in Pyeongtaek $(39.94 \%, 123 / 308)$, Yongin $(38.46 \%, 75 / 195)$ and Osan $(36.02 \%, 58 / 161)$ compared to the overall proportion of admitted patients $(27.63 \%, 851 / 3,080)$. Of all poisoned patients, the proportion of patients admitted to the intensive care unit was higher in Ansan $(18.66 \%, 67 / 359)$ than the overall proportion of poisoned patients $(13.57 \%, 417 / 3,080)$ (Fig. 2C). Mortality was higher in Gwangmyong (4.17\%, 9/216) and Yongin $(2.56 \%, 5 / 195)$ than the overall proportion $(1.43 \%$, $44 / 3,080$ ) (Table 2).

\section{Regional differences in the substances causing acute poisonings}

Analysis of causative substances in poisoned patients from 2006 to 2015 showed that 1,219 (39.58\%) poisoning cases were caused by medical drugs and substances while 1,861 (60.42\%) poisoning cases were caused by non-medical substances. Incidents of poisoning by medical drugs and substances were most commonly caused by antiepileptics, sedative-hypnotics and anti-parkinsonism drugs, and psychotropic drugs, not elsewhere classified (T42, T43) (879 cases, 28.54\%); followed by non-opioid analgesics (T39) (156 cases, 5.06\%); other drugs (T50) (70 cases, 2.27\%); and cardiovascular drugs (T46) (40 cases, 1.30\%). Poisonings by non-medical substances were most commonly caused by contact with a venomous animal (T63) (737 cases, 23.93\%), followed by carbon monoxide (T58) (273 cases, 8.86\%), other substances (T65) (241 cases, 7.82\%), and pesticides (T60) (218 cases, 7.08\%) (Table 3).

The proportion of cases involving antiepileptics, sedative-hypnotics and anti-parkinsonism drugs, and psychotropic drugs, not elsewhere classified (T42, T43) was relatively high in Yongin (32.31\%, 63/195), Suwon (30.27\%, 273/902), and Anyang (30.20\%, 164/543), and the proportion of cases involving cardiovascular drugs (T46) was relatively high in Ansan $(5.97 \%, 4 / 67)$ and Suwon $(3.57 \%$, 4/112), while the proportion of cases involving non-opioid analgesics (T39) was high in Hwasung $(7.81 \%, 5 / 64)$ and Yongin $(11.11 \%$, $2 / 18)$. The proportion of cases involving contact with a venomous animal (T63) was relatively high in Gwangmyeong (43.52\%, 94/216), Pyeongtaek $(30.19 \%, 93 / 308)$ and Osan $(32.92 \%, 53 / 161)$ and the proportion of cases involving pesticides (T60) was relatively high in Pyeongtaek (11.69\%, 36/308), Hwasung (9.60\%, 38/397), and Gwangmyeong $(8.33 \%, 18 / 216)$ compared to that in other regions (Table 3).

Further analysis of causative substances was performed ac-

Table 2. Regional differences in age distributions, characteristics, and clinical courses of patients $(n=3,080)$

\begin{tabular}{|c|c|c|c|c|c|c|c|c|c|c|c|}
\hline \multirow{2}{*}{ Regions } & \multirow{2}{*}{ Total } & \multicolumn{4}{|c|}{ Age $(y r)$} & \multirow{2}{*}{$\begin{array}{c}\text { Sex } \\
\text { Female }\end{array}$} & \multirow{2}{*}{$\begin{array}{c}\text { Marital } \\
\text { status }\end{array}$} & \multirow{2}{*}{$\frac{\text { Intent }}{\text { Intentional }}$} & \multirow{2}{*}{$\begin{array}{c}\text { Admission } \\
\text { rate }\end{array}$} & \multirow{2}{*}{$\begin{array}{l}\begin{array}{l}\text { ICU admis- } \\
\text { sion rate }\end{array} \\
\text { ICU }\end{array}$} & \multirow{2}{*}{$\begin{array}{l}\text { Outcome } \\
\text { Mortality }\end{array}$} \\
\hline & & $\leq 9$ & $10-19$ & $20-64$ & $\geq 65$ & & & & & & \\
\hline Ansan & 359 (11.66) & $55(15.32)$ & $16(4.46)$ & 257 (71.59) & $31(8.64)$ & $188(52.37)$ & 108 (30.08) & $200(55.71)$ & $102(28.41)$ & 67 (18.66) & $3(0.84)$ \\
\hline Anyang & 543 (17.63) & $69(12.71)$ & $34(6.26)$ & $352(64.83)$ & $88(16.21)$ & $327(60.22)$ & 269 (49.54) & $196(36.10)$ & 96 (17.68) & $60(11.05)$ & $3(0.55)$ \\
\hline Hwasung & 396 (12.86) & $65(16.41)$ & $21(5.30)$ & 257 (64.90) & 53 (13.38) & 218 (55.05) & 145 (36.62) & $181(45.71)$ & 115 (29.04) & $64(16.16)$ & $4(1.01)$ \\
\hline Gwangmyeong & $216(7.01)$ & $23(10.65)$ & 24 (11.11) & 122 (56.48) & $47(21.76)$ & 110 (50.93) & 34 (15.74) & $84(38.89)$ & 38 (17.59) & $35(16.20)$ & $9(4.17)$ \\
\hline Osan & $161(5.23)$ & 15 (9.32) & $14(8.70)$ & 116 (72.05) & 16 (9.94) & $95(59.01)$ & $76(47.20)$ & $71(44.10)$ & $58(36.02)$ & $25(16.15)$ & $2(1.24)$ \\
\hline Pyeontaek & $308(10.00)$ & $21(6.82)$ & $11(3.57)$ & $212(68.83)$ & 64 (20.78) & $154(50.00)$ & $127(41.23)$ & 135 (43.83) & 123 (39.94) & 36 (11.69) & $4(1.30)$ \\
\hline Suwon & 902 (29.29) & 119 (13.19) & 77 (8.54) & 595 (65.96) & 111 (12.31) & $513(56.87)$ & 385 (42.68) & 467 (51.77) & $244(27.05)$ & $112(12.42)$ & $14(1.55)$ \\
\hline Yongin & $195(6.33)$ & 34 (17.44) & $8(4.10)$ & $122(62.56)$ & 31 (15.90) & $118(60.51)$ & $84(43.08)$ & $89(45.64)$ & 75 (38.46) & 18 (9.23) & $5(2.56)$ \\
\hline Total & 3,080 & 401 (13.02) & $205(6.66)$ & $2,033(66.01)$ & 441 (14.32) & $1,723(55.94)$ & $1,228(39.87)$ & $1,423(46.20)$ & $851(27.63)$ & 417 (13.57) & $44(1.43)$ \\
\hline
\end{tabular}

Values are presented as number (\%).

ICU, intensive care unit. 
Table 3. The substances causing poisonings for each region $(n=3,080)$

\begin{tabular}{|c|c|c|c|c|c|c|c|c|c|}
\hline Causative substance (agent) & Ansan & Anyang & Hwasung & $\begin{array}{l}\text { Gwang- } \\
\text { myeong }\end{array}$ & Osan & Pyeongtaek & Suwon & Yongin & Total \\
\hline \multicolumn{10}{|l|}{ Drugs, medicaments and biological substances } \\
\hline Hormones (T38) & $2(0.56)$ & $0(0.00)$ & $1(0.25)$ & $0(0.00)$ & $1(0.62)$ & $0(0.00)$ & $4(0.44)$ & $2(1.03)$ & 10 \\
\hline Non-opioid analgesics (T39) & $10(2.79)$ & $21(3.87)$ & $18(4.55)$ & $8(3.70)$ & $10(6.21)$ & $13(4.22)$ & $67(7.43)$ & $9(4.62)$ & 156 \\
\hline Hallucinogens (T40) & $4(1.11)$ & $5(0.92)$ & $0(0.00)$ & $0(0.00)$ & $1(0.62)$ & $1(0.32)$ & $8(0.89)$ & $2(1.03)$ & 21 \\
\hline Cardiovascular drugs (T46) & $10(2.79)$ & $8(1.47)$ & $1(0.25)$ & $0(0.00)$ & $2(1.24)$ & $4(1.30)$ & $14(1.55)$ & $1(0.51)$ & 40 \\
\hline Gastrointestinal drugs (T47) & $5(1.39)$ & $0(0.00)$ & $1(0.25)$ & $0(0.00)$ & $1(0.62)$ & $1(0.32)$ & $4(0.44)$ & $1(0.51)$ & 13 \\
\hline Other drugs (T50) & $16(4.46)$ & $6(1.10)$ & $14(3.54)$ & $8(3.70)$ & $3(1.86)$ & $4(1.30)$ & $16(1.77)$ & $3(1.54)$ & 70 \\
\hline Total & $158(44.01)$ & 209 (38.49) & $153(38.64)$ & $67(31.02)$ & $61(37.89)$ & $100(32.47)$ & $389(43.13)$ & $82(42.05)$ & 1,219 \\
\hline Corrosive substances (T54) & $23(6.41)$ & $25(4.60)$ & $27(6.82)$ & $6(2.78)$ & $10(6.21)$ & $21(6.82)$ & 45 (4.99) & $11(5.64)$ & 168 \\
\hline Soaps and detergents (T55) & $9(2.51)$ & $15(2.76)$ & $7(1.77)$ & $7(3.24)$ & $5(3.11)$ & $3(0.97)$ & $19(2.11)$ & $3(1.54)$ & 68 \\
\hline Metals and inorganic substance (T56,T57) & $1(0.28)$ & $0(0.00)$ & $2(0.51)$ & $0(0.00)$ & $0(0.00)$ & $0(0.00)$ & $4(0.44)$ & $2(1.03)$ & 9 \\
\hline Carbon monoxide (T58) & $63(17.55)$ & $56(10.31)$ & $30(7.58)$ & $4(1.85)$ & $14(8.70)$ & $19(6.17)$ & $76(8.43)$ & $11(5.64)$ & 273 \\
\hline Gases (T59) & $8(2.23)$ & $7(1.29)$ & 17 (4.29) & $0(0.00)$ & $2(1.24)$ & $1(0.32)$ & $6(0.67)$ & $0(0.00)$ & 41 \\
\hline Pesticides (T60) & $27(7.52)$ & $18(3.31)$ & $38(9.60)$ & $18(8.33)$ & $6(3.73)$ & $36(11.69)$ & $60(6.65)$ & 15 (7.69) & 218 \\
\hline Food (T62) & $6(1.67)$ & $6(1.10)$ & $12(3.03)$ & $4(1.85)$ & $4(2.48)$ & $16(5.19)$ & $23(2.55)$ & $1(0.51)$ & 72 \\
\hline Contact with venous animals (T63) & 39 (10.86) & $163(30.02)$ & 67 (16.92) & $94(43.52)$ & 53 (32.92) & 93 (30.19) & $186(20.62)$ & $42(21.54)$ & 737 \\
\hline Unspecified substance (T65) & $21(5.85)$ & $44(8.10)$ & 36 (9.09) & $12(5.56)$ & $5(3.11)$ & $17(5.52)$ & $80(8.87)$ & $26(13.33)$ & 241 \\
\hline Total & 201 (55.99) & $334(61.51)$ & $243(61.36)$ & $149(68.98)$ & $100(62.11)$ & $208(67.53)$ & $513(56.87)$ & 113 (57.95) & 1,861 \\
\hline
\end{tabular}

Values are presented as number (\%).

cording to hospitalization status. Poisoning incidents which needed intensive care were most commonly caused by antiepileptics, sedative-hypnotics and anti-parkinsonism drugs, and psychotropic drugs, not elsewhere classified (T42, T43) (218 cases, 52.15\%), followed by pesticide (T60) (87 cases, 20.81\%) and non-opioid analgesics (T39) (21 cases, 5.02\%). In patients hospitalized through the emergency room, the proportion of cases involving carbon monoxide (T58) was relatively high in Ansan $(8.82 \%, 9 / 102)$ and Anyang $(8.33 \%, 8 / 96)$, while the proportions of cases involving non-opioid analgesics (T39) were relatively high in Osan (13.79\%, 8/58) and Suwon (11.48\%, 28/244). Among patients admitted to the intensive care unit, the proportion of cases involving pesticides (T60) was relatively high in Pyeongtaek $(52.78 \%, 19 / 36)$ (Table 4).

The distribution of overall poisoning cases and some common causative substances are mapped. The frequency of incidents in the same region are expressed by the sizes of the circles (Fig. 3).

\section{DISCUSSION}

Acute poisoning has been a major problem from a medical and socioeconomic perspective. To offer proper treatment for patients with acute poisoning, hospitals need to be aware of the unique characteristics of the region in which they are located. We analyzed the data of 3,080 cases of acute poisoning in 8 cities of Gyeonggi-do province, and identified the differences in the incidence, age distribution, causative agent, and clinical course of poisonings of patients among the regions. This is the first study to propose a method using GIS as an efficient manner to allocate treatment resources.

Hwasung and Yongin had high rates of poisonings in the $\leq 9$ year age group. Therefore, the hospitals in these cities need to be sure that they are well prepared to offer proper treatment for pediatric poisoning. Pediatric patients are defined not only by their young age, but by the differences in types and diversity of causative substance, reason, symptoms, and signs of poisonings..$^{8-13}$ Therefore, the unique circumstances of exposure, clinical effects, diagnostic approach, and therapeutic interventions need to be considered in order to care for pediatric patients with poisoning. ${ }^{14}$ Considering the differences in physiology and pharmacodynamics between pediatric patients and adults, it is necessary to allocate physicians who are able to care for pediatric patients using suitable acute poisoning facilities. The proportion of intentional poi- 
Table 4. Regional differences in common causative substances according to treatment courses



Values are presented as number (\%).

ICU, intensive care unit.

T39 = non-opioid analgesics, T40= hallucinogens, T42 = antiepileptic, sedative-hypnotic and anti-parkinsonism drugs, and psychotropic drugs, not elsewhere classified, T46 $=$ cardiovascular drugs, T50 = diuretics and other unspecified drugs, medicaments and biological substances, T51 = alcohol, T54=corrosive substances T55= soaps and detergents, $\mathrm{T} 58=$ carbon monoxide, $\mathrm{T} 60=$ pesticides, $\mathrm{T} 62=$ seafood and food, $\mathrm{T} 63=$ contact with venomous animals, $\mathrm{T} 65=$ unspecified substances.

sonings in the 10-19-year age group was relatively high in Suwon and Gwangmyeong; programs for suicide prevention are needed for adolescents in these regions."

In Pyeongtaek and Gwangmyeong, the proportion of poisoned patients in the $\geq 65$-year age group was high. Therefore, preparation for elderly poisoning patients is necessary. Renal and liver functions have been shown to decline with age in this group, and are closely related to the severity and prognosis of acute drug poisonings. ${ }^{15-17}$ Considering that elderly patients have higher poi- soning severity scores, higher admission rates in the intensive care unit and higher mortality rates, sufficient medical resources should be allocated for elderly poisoning patients in these regions. ${ }^{18}$

In Ansan, the proportion of intentional poisonings was $55.71 \%$, which was significantly higher than the overall average (46.20\%). The percentages of carbon monoxide poisonings and cardiovascular drug poisonings as the causative substance were also higher in Ansan than in the other regions. The admission rate of patients 

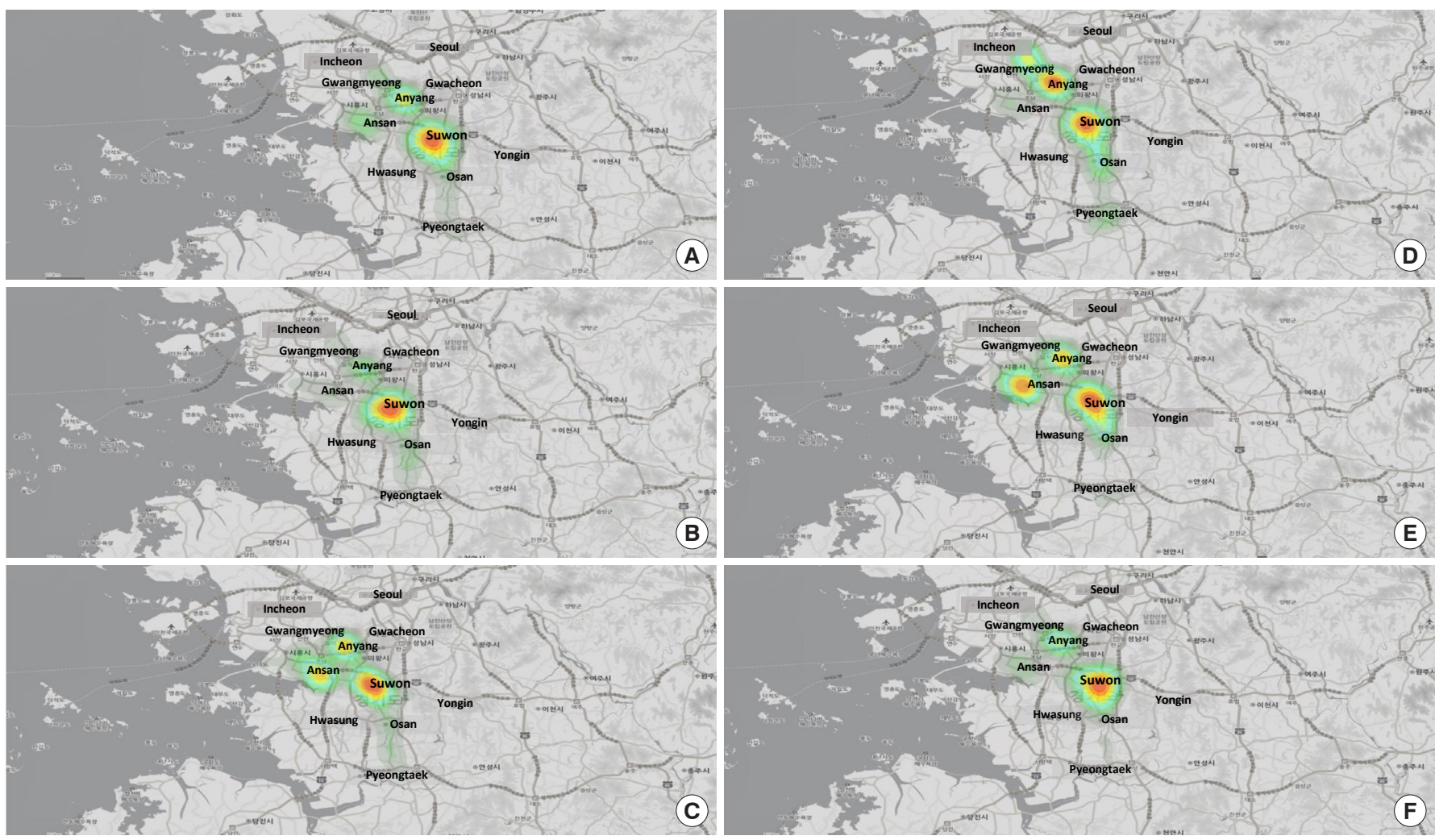

Fig. 3. The regional distribution (Depending on the type of causative substances, regional distributions of acute poisoning were different. Acute poisoning cases of all causative substances frequently occurred in Suwon, being (D) contact with venomous animals in Anyang and (E) carbon monoxide poisoning in Ansan. In the maps of acute poisoning, green means lower incidences, red means higher incidences.) of cases of acute poisoning with causative substances. (A) Sedative-hypnotics (T42), (B) non-opioid analgesics (T39), (C) cardiovascular drugs (T46), (D) contact with venomous animals (T63), (E) carbon monoxide (T58), and (F) unspecified substances (T65).

to the intensive care unit in Ansan was the highest among regions enrolled in our study. These results may indicate the possibility of a significant amount of patients with poisoning by cardiovascular drugs such as beta-blockers or calcium channel blockers and carbon monoxide poisonings in Ansan. It may be necessary to ensure the availability of antidotes for beta-blocker or calcium channel blocker poisonings in these hospitals. In addition, extracorporeal elimination modalities and accessibility to hyperbaric oxygen therapy devices are needed for this region.

Sub-analysis of causative substances according to hospitalization status showed that the proportion of poisoning by sedative drugs was high generally. There were differences among the regions. The proportion of poisoning by pesticides was high in Pyeongtaek, Hwasung, and Gwangmyeong, particularly in Pyeongtaek, where more than half the patients admitted to the intensive care unit had pesticide poisoning. Therefore, it is necessary to prepare for severe pesticide poisonings in such regions.

Because of the financial limitations, hospitals in these regions may not have the necessary resources to prepare for the types of poisonings unique to their area. Gathering and combining a mul- titude of resources at a single place, such as poison centers, might be needed to cover multiple regions. The implementation of GIS technology in this study using data from the NEDIS of Korea enabled us to see the prevalence of poisonings in several regions according to the causative substances at a glance. ${ }^{19-21}$ Therefore, when planning to establish a poison center, using GIS may be helpful for determining the precise location according to the causative substances of poisoning.

Our study has several limitations. Although the number of cases used in this study was similar to those of nationwide studies conducted before, our data were not representative of the poisoning status of the whole nation because the data were only extracted from 8 cities in Gyeonggi-do province. 'We performed this study based on the International Classification of Diseases 10th revision classification. However, this classification could not provide more details for causative substances. For example, the proportion of 'Paraquat' in pesticide poisonings was not available. The implementation of mapping for poisonings was coarse, lacking details such as scales of the map or legends because we used a web application programming interface that was free of charge. 
Therefore, the real-world application of the results of this study may have some limitations. However, efforts and attempts to introduce GIS as one of the research tools for recognizing the geographical distribution of acute poisonings could be meaningful. Statistical considerations are lacking in this study. Although some differences in the characteristics of poisoned patients between 8 cities were noted, more statistically significant results would have made the findings even more relevant. However, this study is meaningful in that it showed the differences in characteristics of poisonings among cities close to each other.

In summary, the characteristics of patients with acute poisonings were different even in 8 cities which were located in the same province. Stockpiling and preparation of treatment resources for effective care, such as the timely use of an appropriate antidote to patients with acute poisoning, should be tailored to the region's characteristics in each hospital. Although this study was not nationwide, the methods and concepts used in this study could be helpful to distribute medical resources appropriately to each region and their hospitals if conducted using national data.

\section{CONFLICT OF INTEREST}

No potential conflict of interest relevant to this article was reported.

\section{REFERENCES}

1. Kim K, Choi JW, Park M, Kim MS, Lee ES. A nationwide study of patients hospitalised for poisoning in Korea based on Korea National Hospital Discharge In-Depth Injury Survey data from 2005 to 2009. BMJ Open 2015;5:e008823.

2. Megarbanea $B$, Alaziab $M$, Bauda F. Severe poisoning in adults: epidemiology, definition, and criteria of admission in intensive care units. Reanimation 2006;15:354-63.

3. Erickson TB, Thompson TM, Lu JJ. The approach to the patient with an unknown overdose. Emerg Med Clin North Am 2007; 25:249-81.

4. Lee $\mathrm{JH}, \mathrm{Oh} \mathrm{SH}$, Park KN, et al. Epidemiologic study of poisoned patients who presented to the emergency department of a high end medical facility in Seoul 1998 2009. J Korean Soc Clin Toxicol 2010;8:7-15.

5. Dummer TJ. Health geography: supporting public health policy and planning. CMAJ 2008;178:1177-80.

6. National Emergency Medical Center. 2013 Yearbook of emergency medical statics [Internet]. Seoul: National Emergency Medical Center; 2018 [cited 2019 May 18]. Available from: http://media.nemc.or.kr/file/download_file_encrypt.do?fileite $\mathrm{mno}=\mathrm{cb} 321 \mathrm{dce} 628247065829812 \mathrm{c} 924 \mathrm{a} 4958$.

7. World Health Organization. International statistical classification of diseases and related health problems 10th revision (ICD10)-WHO version for 2016 [Internet]. Geneva: World Health Organization; 2016 [cited 2017 Jan 30]. Available from: http: //apps.who.int/classifications/icd10/browse/2016/en\#/XIX.

8. Woo JH, Ryoo E. Poisoning in korean children and adolescents. Pediatr Gastroenterol Hepatol Nutr 2013;16:233-9.

9. Lee MJ, Park JS. Clinical aspects of injury and acute poisoning in Korean pediatric patients. Korean J Pediatr 2008;51:116-21.

10. Eum JP, Suh JS, Kim HM. Clinical analysis of acute drug intoxication and foreign body ingestion in Wonju: comparison between the 1990s and the 2000s. Korean J Pediatr 2007;50: $138-42$

11. Han CS, Jeon WC, Min YG, Choi SC, Lee JS. Retrospective analysis on the clinical differences of children and adolescents treated for acute pediatric poisoning in an emergency department? J Korean Soc Emerg Med 2013;24:742-9.

12. Gummin DD, Mowry JB, Spyker DA, Brooks DE, Fraser MO, Banner W. 2016 Annual Report of the American Association of Poison Control Centers' National Poison Data System (NPDS): 34th Annual Report. Clin Toxicol (Phila) 2017;55:1072-252.

13. Almond C. Children are not little adults. Aust Nurs J 1998;6:1-4.

14. Calello DP, Henretig FM. Pediatric toxicology: specialized approach to the poisoned child. Emerg Med Clin North Am 2014; 32:29-52.

15. Muhlberg W, Becher K, Heppner HJ, Wicklein S, Sieber C. Acute poisoning in old and very old patients: a longitudinal retrospective study of 5883 patients in a toxicological intensive care unit. Z Gerontol Geriatr. 2005;38:182-9.

16. Muhlberg W, Platt D. Age-dependent changes of the kidneys: pharmacological implications. Gerontology 1999;45:243-53.

17. Kim BK, Jung SY, Jung KY. Characteristics of elderly patients with acute poisoning. J Korean Soc Clin Toxicol 2010;8:61-8.

18. Lee WJ, Choi SM, Kyong YY, et al. Clinical analysis of acute poisoning in elderly patients. J Korean Geriatr Soc 2009;13: 24-30.

19. Schuurman N, Cinnamon J, Crooks VA, Hameed SM. Pedestrian injury and the built environment: an environmental scan of hotspots. BMC Public Health 2009;9:233.

20. Walker BB, Schuurman N, Hameed SM. A GIS-based spatiotemporal analysis of violent trauma hotspots in Vancouver, Canada: identification, contextualization and intervention. BMJ Open 2014;4:e003642.

21. Tahouri A, Tahouri J, Boutlib F, Achour S, Lyoussi B. Epidemiological and clinical aspects of carbon monoxide poisoning in Fez city. J Pharmacol Toxicol 2017;12:191-200. 